AS CORES DO PASSA NA AMAZÔNIA: O PATRIMÔ RQUEOLÓGICO NO ARTESAN DA VILA DE JOANES, ILHA MARAJÓ, BR 


\section{AS CORES DO PASSADO NA AMAZÔNIA: O PATRIMÔNIO ARQUEOLÓGICO NO ARTESANATO DA VILA DE JOANES, ILHA DO MARAJÓ, BRASIL}




\title{
AS CORES DO PASSADO NA AMAZÔNIA: O PATRIMÔNIO ARQUEOLÓGICO NO ARTESANATO DA VILA DE JOANES, ILHA DO MARAJÓ, BRASIL
}

\author{
Resumo \\ $\mathrm{O}$ artigo trata das relações entre os moradores da vila de Joanes, na \\ ilha do Marajó, e o patrimônio arqueológico, considerando a incorpora- \\ ção do repertório icônico da arqueologia no artesanato produzido pelas \\ artesãs locais. Com base nesse estudo de caso, concluo que, mais do \\ que informar sobre as percepções locais acerca do passado, as imagens \\ criadas pelas artesãs revelam aspectos de relações sociais estabelecidas \\ no presente.
}

Palavras-chave: artesanato, patrimônio arqueológico, Amazônia

THE COLORS OF THE PAST IN AMAZONIA: THE ARCHAEOLOGICAL HERITAGE IN THE HANDICRAFTS OF VILA DE JOANES, MARAJO ISLAND, BRAZIL

\begin{abstract}
This paper considers the relationships between the local communities of Vila de Joanes, Marajó Island, and the archaeological heritage, regarding the incorporation of the iconic repertoire of archaeology in handicrafts produced by local artisans. Based on this case study, I conclude that, in addition to informing about local perceptions of the past, the images created by the artisans reveal aspects of the social relations in the present.
\end{abstract}

Keywords: handicraft, archaeological heritage, Amazon 


\section{LAS COLORES DEL PASADO EN AMAZONÍA: EL PATRIMO- NIO ARQUEOLÓGICO EN LA ARTESANÍA DE LA VILA DE JO- ANES, ISLA DEL MARAJÓ, BRASIL}

\section{Resumen}

El artículo trata de las relaciones entre los habitantes de Vila de Joanes, en la isla de Marajó, y el patrimonio arqueológico, y se considera la incorporación del repertorio icónico de la arqueología en las artesanías producidas por artesanas locales. Con base en este estudio de caso se llegó a la conclusión que, además de informar sobre de las percepciones locales sobre el pasado, las imágenes creadas por las artesanas revelan aspectos de las relaciones sociales en el presente.

Palabras-clave: artesanía, património arqueológico, Amazonía

Endereço da autora para correspondência: Universidade Federal do Pará, Programa de Pós-graduação em Antropologia. Rua Augusto Correa, 1, Campus Básico, Guamá. CEP 66075-110, Belém/PA, Brasil. E-mail: marciabezerrac14@gmail.com 


\section{INTRODUÇÃO}

O estudo das representações da Arqueologia tem atraído um crescente número de pesquisadores (Bezerra 2012a; Molyneaux 1997; Moser \& Gamble 1997; Russel 2006; Schaan 2011; Zarankin \& Salerno 2010). Moser (2001), Holtorf (1997; 2006, 2007a, 2007b) e Russel (1997), entre outros, têm dado especial atenção às formas de representação visual da disciplina na cultura popular. Hodder (2001) discute a existência de uma Poética da Arqueologia fundamental para a investigação sobre os modos e estilos de representação do conhecimento produzido pela disciplina na construção do passado.

As reflexões sobre as narrativas do passado têm sugerido que essas reconstruções, simulações, interpretações e representações visuais fazem parte do próprio processo de pesquisa (Moser 2001: 281). Uma mesma matriz de informações sobre um sítio ou um objeto arqueológico pode ser a fonte criadora de múltiplas visões sobre o passado, indicando que os contornos temporais e simbólicos do registro arqueológico se estendem até o presente, tornando-se parte integrante dele.

A compreensão do contexto de produção dessas narrativas possibilita reconhecer o impacto do conhecimento científico na sua composição (Holtorf 2006, 2007a, 2007b; Moser 2001), promovendo o entendimento das perspectivas sobre a ciência e o passado, o que contribui para os debates acerca do papel social da Arqueologia no mundo contemporâneo.

É a partir dessa perspectiva que anali- so o discurso icônico da Arqueologia presente no artesanato produzido na Vila de Joanes, Ilha do Marajó. Com base nesse estudo de caso, considero que as imagens criadas pelos artesãos são uma ressonância do passado e concluo que, mais do que informar sobre as percepções locais acerca do passado, essas elaborações revelam aspectos de relações sociais estabelecidas no presente (Bezerra no prelo/b). Inicio apresentando o contexto da pesquisa realizada na Vila de Joanes para, em seguida, apontar algumas questões que envolvem o turismo e as comunidades locais e, por fim, trato do estudo de caso: o artesanato produzido pela AERAJ - Associação Educativa Rural e Artesanal da Vila de Joanes, objeto de projeto de pesquisa desenvolvido em 2011, com apoio da Funarte/MinC (Bezerra 2011).

\section{- CONTEXTO e A PESQUISA DE CAMPO NA VILA DE JOANES}

A Vila de Joanes situa-se na região nordeste da Ilha de Marajó, localizada na mesorregião do arquipélago de mesmo nome, sendo um dos cinco distritos do município de Salvaterra ${ }^{1}$, que tem população estimada em 20.572 habitantes (IBGE 2012) (Figura 1). A principal fonte econômica de Salvaterra é a cultura do abacaxi (cerca de 30.000 frutos/h) e, em segundo lugar, a da mandioca $(600 \mathrm{~kg} / \mathrm{h})$. O plantio de milho, arroz e feijão é reservado para a subsistência familiar. A maior parte da população (61\%) do arquipélago de Marajó vive de atividades agrícolas de pequena escala e da criação dos reba- 
nhos bubalinos e bovinos. O arquipélago teve o menor Índice de Desenvolvimento Humano (IDH) - relativo à saúde, educação e renda - do estado (0.63\%) em 2000, indicando a maior

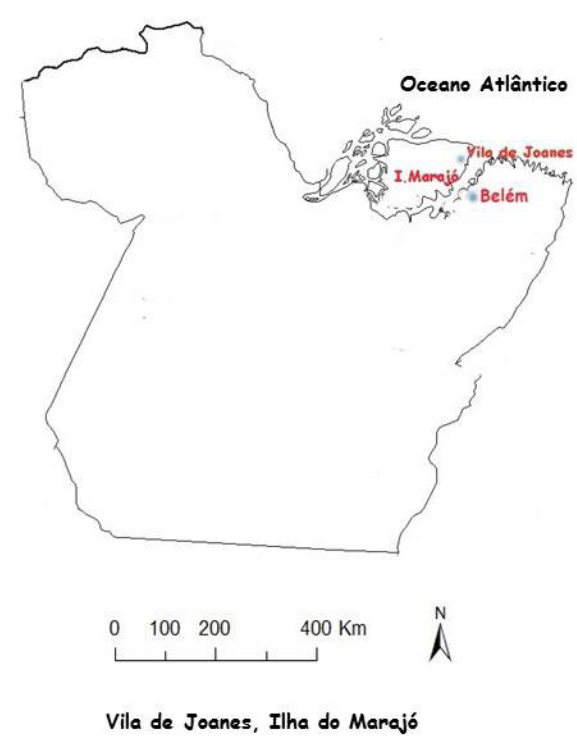

Vila de Joanes, Ilha do Marajó assimetria entre todos os valores do IDH do Pará (Pará 2012). A população do arquipélago cresce 2,05\% ao ano, levando a uma situação de significativa vulnerabilidade econômica e social.

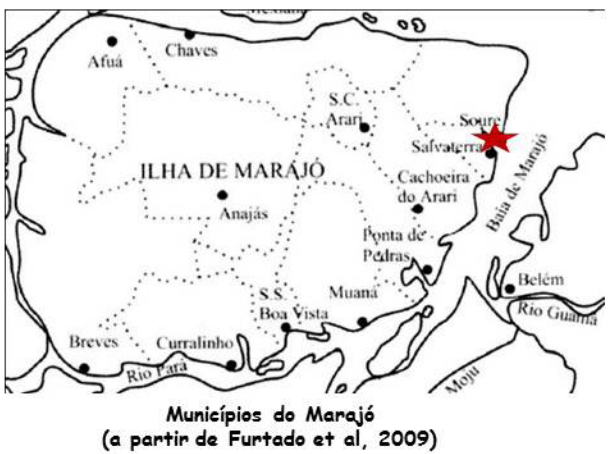

Figura 1 - Mapa de localização da Vila de Joanes.

Joanes é uma vila de pescadores localizada na área rural a $17 \mathrm{~km}$ da sede da cidade de Salvaterra. Com aproximadamente 1.800 moradores $^{2}$ a vila constitui uma comunidade de pequena escala, na qual as ligações de parentesco e as "relações face a face" (Feldman-Bianco 2010: 30) unem parte significativa da população. A economia é baseada na pesca, na agricultura de subsistência e em atividades ligadas ao turismo. No verão amazônico, particularmente no mês de julho, a vila recebe grande fluxo de turistas - brasileiros e estrangeiros - atraídos pelas praias, igarapés e, em menor escala, pelas ruínas que compõem o sítio arqueológico de Joanes. O sítio de Joanes (PA-JO-46) reúne vestígios de ocupação pré-colonial e histórica. A Igreja de Nossa Senhora do Rosário - hoje em ruínas - foi implantada sobre um antigo aldeamento indígena, por uma missão religiosa que se instalou na ilha no século XVII (Lopes 1999). A lógica de ocupação do espaço da missão é, em certa medida, refletida na paisagem atual. No passado, a construção da igreja instaurou o núcleo principal da missão - o lócus colonial. Hoje, no entorno de suas ruínas, a igreja "nova" (assim chama- 
da pelos moradores em contraponto às ruínas da "igreja velha"), o salão de festas da igreja, a escola e a praça cons- tituem uma paisagem de sociabilidade experienciada cotidianamente pelas comunidades locais (Figura 2).

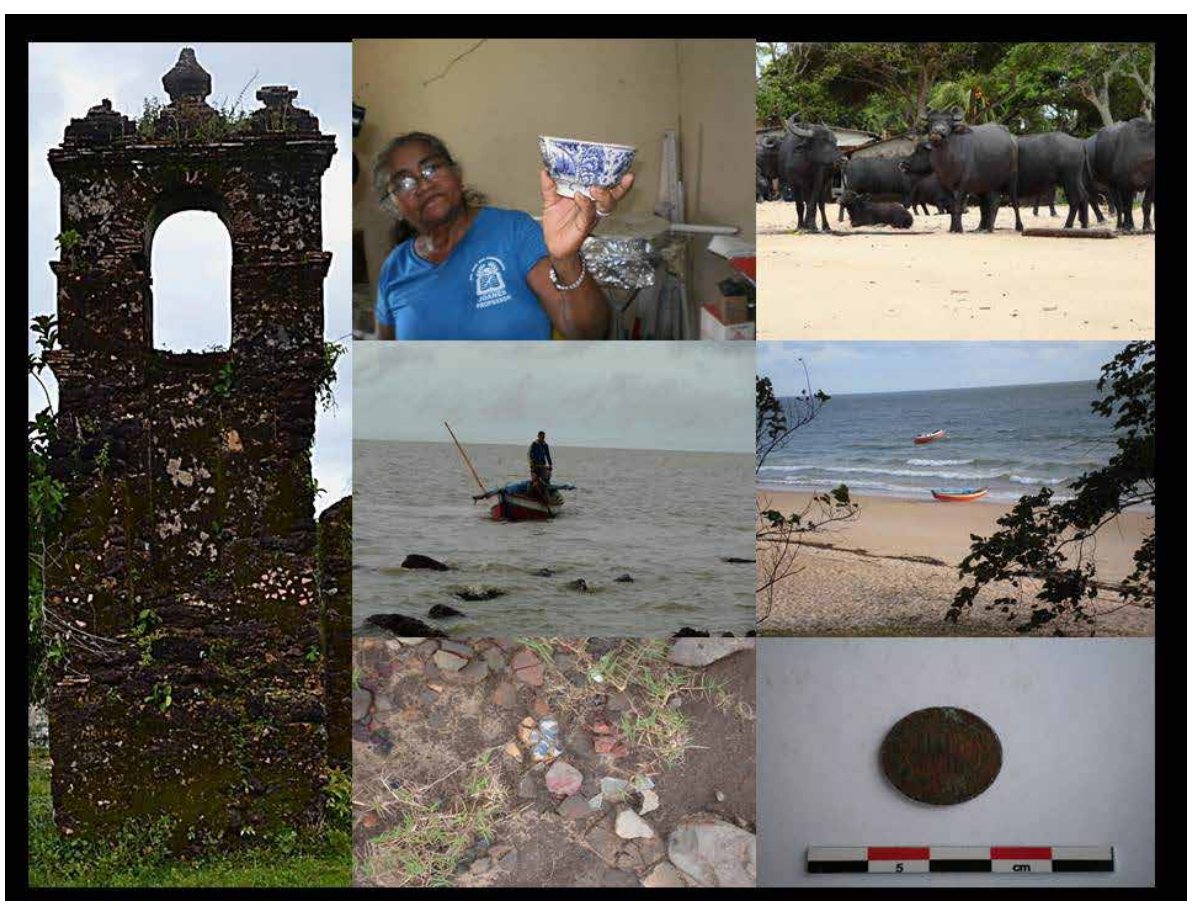

Figura 2 - Cenas da vida em Joanes. Fotos Marcia Bezerra, 2009 e 2010.

Há várias comunidades em Joanes, mas a distinção que mais se destaca diz respeito à categoria "filhos de Joanes", ativada pelos moradores em oposição à categoria "forasteiros", já discutidas em trabalhos anteriores (Bezerra 2011, 2012) ${ }^{3}$ a partir das reflexões de Elias e Scotson (2000) sobre os "estabelecidos" e "outsiders". A primeira categoria se refere àqueles nascidos na vila; a segunda comporta os oriundos do "estrangeiro", seja do Brasil (de outras localidades do Pará e de outros estados brasileiros), seja de outros países, sobretudo da Europa - em especial da Bélgica". Os "forasteiros" desempenham atividades comerciais, sendo proprietários de armazéns ("vendas"), pousadas, restaurantes e pequenos armarinhos, entre outros estabelecimentos, nos quais os moradores são empregados e/ou clientes. Em alguns deles, há a prática da anotação das despesas no "caderno", onde as compras são registradas para posterior pagamento ${ }^{5}$.

Esse sistema de endividamento constitui um forte mecanismo de controle fortalecido durante a época do defeso (IBAMA 2012), quando ocorre a suspensão da atividade pesqueira para a proteção das espécies. Segundo alguns pescadores, com os constantes atrasos no pagamento do seguro defeso, assegurado pela Lei $\mathrm{N}^{\circ} 10.779$, de 25 
de Novembro de 2003 (Brasil 2003), a única alternativa para o suprimento de suas necessidades básicas, durante esse período, é a sujeição ao sistema de endividamento no "caderno". Essa situação contribui para a condição de vulnerabilidade e para a oposição entre as duas categorias criadas pelos moradores.

De um lado, os "filhos de Joanes" reclamam os seus direitos nas tomadas de decisão sobre problemas da vila, enfatizando a sua origem no lugar; de outro, alguns "forasteiros" reivindicam os seus direitos ao lugar, ressaltando a sua capacidade para a resolução dos problemas locais. Assim, essas categorias identitárias são acionadas em várias ocasiões, dentre elas as que envolvem os patrimônios locais.

As ruínas são mobilizadas na construção das identidades em Joanes, tanto por "filhos de Joanes" quanto por "forasteiros". A sua incorporação acontece quando a identidade da vila, em contraste com a sede do município de Salvaterra, está em jogo (Bezerra prelo/a). Um dos casos em que há um alinhamento das duas categorias é quando se demanda a construção de um museu na área das ruínas, que serviria para "contar a história de Joanes" (Ferreira \& Bezerra 2013: 174). Contudo, ao se discutir a gestão do museu, "filhos de Joanes" e "forasteiros" se dividem novamente. Os primeiros teriam direito sobre a gestão por "herança"; os últimos, pela suposta competência para "cuidar" do patrimônio. Essas disputas se capilarizam por outros contextos locais, como aponto mais adiante.

\section{"VOCÊ ESTÁ QUASE VIRANDO UMA 'FILHA DE JOANES'”}

Essa frase foi dirigida a mim por T.D., um antigo morador da vila, muito respeitado por todos e referência importante em Joanes. Isso ocorreu cerca de três anos após ter iniciado minhas pesquisas na vila. Minha chegada em Joanes se deu no âmbito de projeto coordenado por Fernando Marques e por mim (Marques \& Bezerra 2009) como continuação de um projeto desenvolvido por Denise Schaan e Fernando Marques, em 2006 (Schaan \& Marques 2006, 2012). Ambos os projetos foram financiados pelo Instituto do Patrimônio Histórico e Artístico Nacional - Iphan e tinham como objetivo realizar pesquisas arqueológicas, desenvolver ações de Educação Patrimonial e colocar placas de sinalização turística no sítio arqueológico de Joanes. O projeto de 2006 se desenvolveu em meio a um cenário de disputas políticas internas, acarretando uma série de complexas situações enfrentadas pela equipe de Arqueologia (ver Schaan \& Marques 2012). Em 2008 ainda se percebia certa ressonância dos acontecimentos anteriores, mas, aos poucos, um realinhamento das "linhas de força" (Bourdieu 2002) locais mudou o panorama político na vila, amenizando as relações e tornando a inserção no campo mais tranquila.

Após a conclusão desse primeiro projeto conduzi outras pesquisas em Joanes, uma delas ainda em andamento, todas voltadas para o mapeamento das relações dos moradores com o patrimônio arqueológico. Es- 
ses projetos desenvolvidos ao longo de cinco anos me permitiram observar a intrincada teia dessas relações. Propus, em trabalhos anteriores (Bezerra 2011, 2012), que determinadas práticas locais, como o colecionamento de artefatos arqueológicos, considerado pelo Estado como ameaça ao patrimônio, fossem reconhecidas como formas singulares de fruição com o passado. A partir das narrativas memoriais dos moradores, compreendi que as nuances de suas representações sobre o passado e sobre a ideia de museu, por exemplo, tinham um impacto significativo nas percepções e atitudes referentes ao sítio de Joanes.

A ideia de museu em Joanes está diretamente ligada ao tema do turismo. Há um crescente discurso sobre a apropriação do patrimônio arqueológico pelo turismo na vila (Airoza \& Bezerra 2011; Ferreira 2012; Ferreira \& Bezerra 2012). As ruínas são visitadas por turistas, em geral, hospedados na sede do município Salvaterra - ou em Soure. Os turistas que se instalam nas pousadas em Joanes não são incentivados a visitá-las e, na maior parte das vezes, sequer sabem de sua existência. A oferta de atrativos limita-se às praias, passeios de barcos por igarapés e caminhadas por trilhas.

Muitos visitantes que chegam à área das ruínas "escalam" a torre da igreja para tirar fotografias e passeiam e/ou estacionam veículos sobre o sítio. Os moradores reclamam dos turistas $\mathrm{e}$ tentam evitar essas atitudes. Recentemente, um grupo local organizou um mutirão - uma prática comum na vila - e cercou com estacas de madeira a área das ruínas, visando à sua proteção (Ferreira 2012: 103). Apesar disso, há uma expectativa positiva com relação ao desenvolvimento do turismo na vila. Alguns moradores acreditam que a instalação de infraestrutura turística nas praias é a solução para o incremento da visitação e da economia local. Segundo Ferreira \& Bezerra (2012: 10), uma parte dos moradores considera que:

"o que deve ser constituído na Vila é um memorial onde se apresente aos visitantes a "história de Joanes" a partir da exposição dos vestígios arqueológicos. Para outros, o museu é um lugar para se exibir relíquias, coisas diferentes que chamem à atenção dos visitantes. Ao falar desses objetos curiosos, geralmente eles mencionam o bezerro de duas cabeças exposto no Museu do Marajó, localizado no município de Cachoeira do Arari, também na Ilha do Marajó. Há também os que veem na constituição do museu a possibilidade de potencializar o turismo em Joanes, gerando emprego e renda para a população local”.

Ferreira (2012: 75) discute sobre a necessidade de se evitar a adjetivação dicotômica de "bandidos e/ou mocinhos" no âmbito do turismo cultural. A autora ressalta as complexidades dessas relações, especialmente quando se trata da inserção de comunidades locais no mundo do trabalho no setor turístico. Ela ainda afirma que o turismo gera emprego e renda, mas lembra de que, em geral, os residen- 
tes locais atuam em subempregos, o que os mantêm em desvantagem econômica e social. Barretto (2003: 25), ao tratar das relações entre turistas e comunidades receptoras, afirma que um dos problemas do fenômeno do turismo é que ele "não acontece entre iguais".

Gmelch (2003: 25), ao refletir sobre o turismo em Barbados a partir dos moradores empregados no setor, confirma essa assimetria nas relações e considera que a distinção desse tipo de atividade profissional é a interação estabelecida entre visitantes e residentes. Diz ele:

"Workers, who are mostly from modest educational and social backgrounds, intermingle with guests from distant lands and cultures who have widely different lifestyles and levels of income. (...) one is at leisure while the other is at work. One has economic assets but little knowledge of the local culture, while the other has cultural capital but little money. One is usually white and the other usually black. One is the First World and the other from the developing or Third World".

O autor (Gmelch 2003: 25) ainda sublinha que os encontros provocados pelo turismo são em sua maioria "transitórios, não repetitivos e assimétricos" (a partir de Cohen 1984, tradução minha). Gmelch também lembra que essas relações de poder têm levado alguns autores a considerar o turismo como uma forma de neocolonialismo ou "leisure imperialism" (Gmelch 2003: 35 a partir de Hiller 1976; Crick 1989 e Chambers 1990).
Portanto, ainda que não concorde com a "satanização" do turismo (Bezerra 2012c), entendo a necessidade de refletirmos sobre ele como uma ação a serviço de uma ideia de desenvolvimento, nem sempre sustentável, e que provoca impactos de toda ordem nas populações locais ${ }^{6}$. Tejedor (2009: 42), ao discutir sobre o turismo, trata desse impacto:

"el turismo modifica substancialmente las culturas locales nativas y muy especialmente sus rasgos más singulares, pues explotados por um mercado turístico ávido de objetos y hechos coloristas y exóticos, se difuminan como fuente de identidade cultural, perdendo em muchos casos cualquier sentido".

Essa "fonte de identidade cultural" encontra no artesanato produzido nesses contextos um manancial de representações e significados que são reelaborados de forma a produzir objetos que imitam os autênticos, que criam "ex-novos" (Tejedor 2009) ou que inventam tradições, tal como proposto por Schaan (2006), nos termos de Hobsbawm \& Rangers (1984), para o contexto amazônico.

O artesanato confeccionado e comercializado por comunidades locais é um mediador das relações estabelecidas no âmbito do turismo, mas também fora dele, como explico mais à frente. As imagens garimpadas de diversas fontes são reorganizadas, reconfiguradas e ressignificadas, de acordo com a perspectiva individual do artesão, da sua comunidade de origem e da visão do outro, no caso 
o turista. Assim, as representações que reúnem imagens, informações e histórias são impressas/expressas nos/pelos objetos que, carregados de nexos, agem sobre as pessoas produtores e consumidores/artesãos e turistas -, engendrando uma interação complexa que vai ao encontro do que Tejedor (2009: 45) chama de "acto comunicativo". O autor afirma que o turismo entendido como "acto comunicativo" amplia a mera relação de compra e venda para tornar-se um processo em que se articulam "resemantizaciones, reapropriaciones, interaciones dialógicas". Nesse "acto comunicativo", cada ator aciona o seu repertório de representações sobre o próprio mundo e sobre o mundo do outro, num constante exercício de alteridade. $\mathrm{Na}$ América Latina, o turismo envolvendo o patrimônio arqueológico tem agido como amálgama diacrítico de identidades e empoderado comunidades locais (ver coletânea de artigos em Silverman 2006).

No caso da Vila de Joanes as narrativas visuais sobre o passado amazônico, em particular o marajoara, são rearranjadas e compõem as identidades, que são reafirmadas no turismo instrumentalizado como estratégia política nas disputas entre as comunidades locais. $\mathrm{O}$ acervo imagético marajoara tem extensa capilaridade e faz parte da "identidade "paraense"", já densamente discutida por Schaan em artigo no qual reflete sobre a cerâmica marajoara como ícone dessa identidade (2012). Em seu texto, Schaan trata da "estética marajoara" a partir do repertório encontrado, entre outros, na cerâmica do Paracuri, em Icoaraci, em muros de casas, camisetas e até num telefone público, na ilha de Mosqueiro, e cujo formato é o de uma urna marajoara (a esse respeito ver também Barreto 2013).

Em Joanes não é diferente. $\mathrm{O}$ discurso iconográfico do passado marajoara está estampado em diversos locais da vila, especialmente naqueles expostos aos olhares externos, como na principal pousada local, no salão de festas localizado na praça da vila e, mais recentemente, no artesanato vendido aos turistas. A iconografia marajoara encapsula a imaginária local composta por figuras de pescadores, barcos, igarapés, rios e das ruínas do sítio de Joanes (Figura 3). Os motivos da cerâmica marajoara também emolduram o imaginário fantástico da Amazônia, como a Matinta Pereira e o Boto, nos muros da vila. Essas imagens compõem paisagens de pertencimento que se sobrepõem, se encaixam umas nas outras, em camadas do tempo, pois "eventos do passado emergem à luz do presente a partir das sutilezas do caráter fabulatório (....) revelando facetas da ocupação do Marajó" e indicando "as formas sensíveis de agenciamentos das coisas e das pessoas" (Silveira \& Bezerra 2012: 142-143). Os objetos produzidos pelo grupo de artesãs da Vila de Joanes fundem todas essas narrativas e revelam a relação dos moradores com o passado (re)criado por eles e comunicado por meio de produtos vendidos aos turistas. 


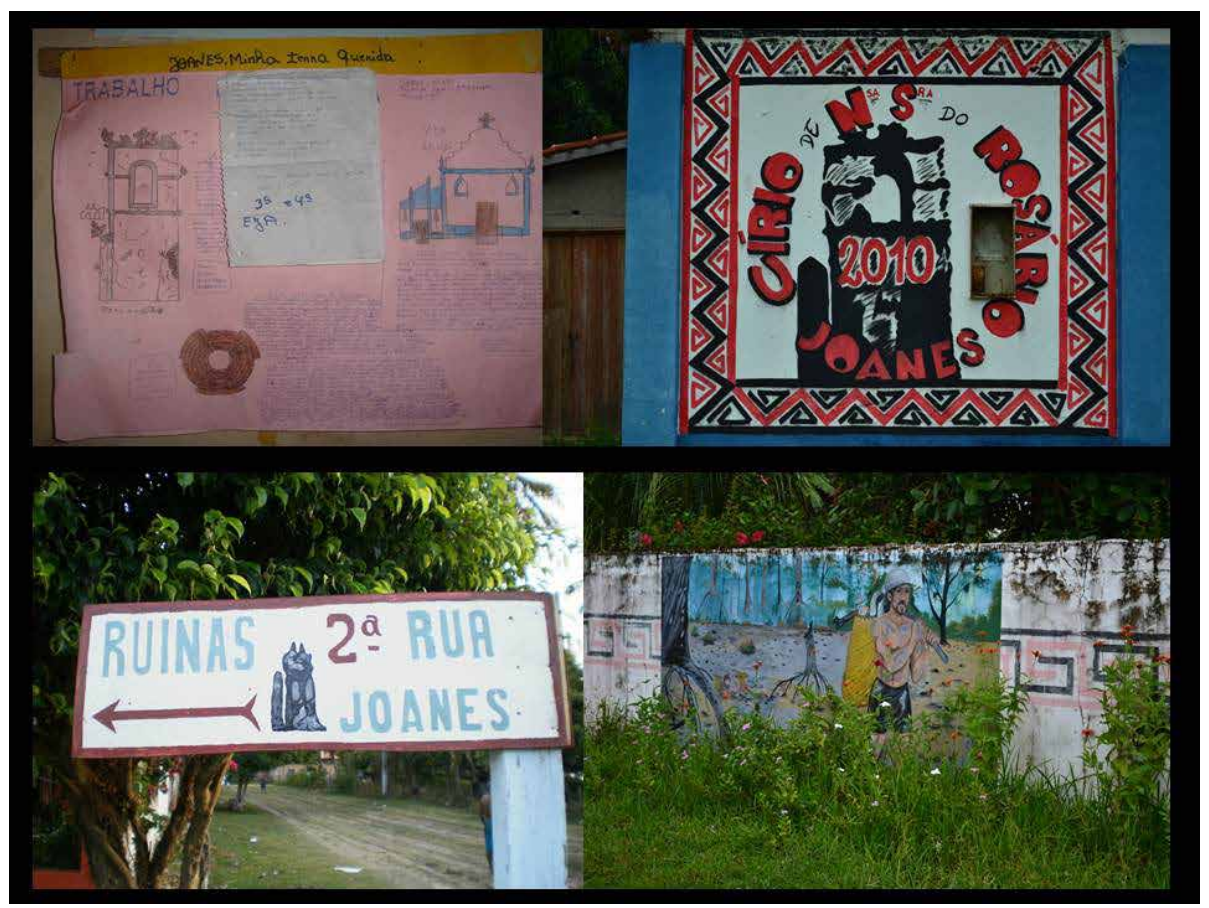

Figura 3 - Imagens das ruínas e do muro pintado em Joanes. Fotos Marcia Bezerra, 2010.

Barreto (2013: 117), ao discutir sobre o artesanato produzido na Amazônia a partir da cultura material arqueológica, argumenta que:

"as dinâmicas da comunicação visual contemporâneas são postas em ação, sem realmente aproveitar ou dialogar a capacidade comunicativa original do objeto, pautada pelas intenções por trás do projeto original e seu contexto no passado arqueológico. No entanto, muitos dos objetos replicados, copiados, transformados, possuem uma intensa capacidade agentiva de comunicação. O uso que se faz assim do repertório do material arqueológico nada tem a ver com a transmissão de conhecimentos sobre culturas passadas, mas ao contrário, vai na direção de sua negação e esvaziamento de significados".
Schaan (2006: 27) também considera que há um distanciamento entre o conhecimento produzido pela Arqueologia e as intepretações livres dos artesãos sobre a cultura material do passado:

"Nesse processo de recuperação de uma estética antiga, novos significados lhe são atribuídos, mediados pelo discurso arqueológico, pela história oral e pela imaginação popular. Esse processo, sempre em construção, parece seguir uma lógica capitalista onde a produção e venda de objetos decorativos se potencializa graças ao acoplamento de um valor cultural. Na medida em que os significados são negociados com base em interesses econômicos, entretanto, a lógica do lucro impõe os limites e possibilidades da reconstrução histórica, chegando- 
-se a um resultado bastante diferente daquele mediado pelo conhecimento científico".

Muito embora concorde com ambas as autoras, optei por refletir sobre o resultado dessas reconstruções, sejam elas próximas ou distantes do discurso da ciência. Creio que o estudo do repertório imagético elaborado a partir de várias fontes - científicas ou não - além de colaborar para a problematização das relações entre as comunidades locais e o patrimônio arqueológico também contribui para as reflexões sobre o nosso papel nesse processo, uma vez que, como já ressaltado por Schaan (2006: 27), entre outros, o nosso trabalho não se encerra com as pesquisas e a publicação de seus resultados, mas se estende por meio das "consequências e desdobramentos (...) da difusão do conhecimento, que dizem respeito à relação que se estabelece entre cientistas sociais e público." Nesse sentido, é a partir da minha relação com os moradores da Vila de Joanes que discuto o lugar do patrimônio arqueológico no artesanato produzido pela AERAJ - Associação Educativa Rural e Artesanal da Vila de Joanes - e os desdobramentos que sua apropriação e recriação têm na vida social da vila.

\section{A PESQUISA NA ASSOCIAÇÃO EDUCATIVA RURAL E ARTESANAL DA VILA DE JOANES/AERAJ}

A pesquisa conduzida na AERAJ, no ano de 2011, teve como principal objetivo a problematização da incorporação da imagem das ruínas que constituem o Sítio Histórico de Joanes (PA-JO-46) no artesanato ali produzido. Como já dito anteriormente, o sítio é formado por repertório material associado aos indígenas e aos europeus, além das ruínas da Igreja de Nossa Senhora do Rosário. O material analisado por Lopes (1999: 119), coletado em uma área de descarte do sítio, incluía louça e metais, além de cerâmica indígena, cabocla e de torno, que apontam para o contato entre missionários religiosos e nativos, no século XVII.

Essa paisagem em ruínas que ecoa a confluência de mundos distintos no passado é o centro das disputas sobre o patrimônio local hoje. Os moradores têm intenso processo de fruição com essas coisas do passado - seja pela prática do colecionamento de objetos, pela elaboração de narrativas fantásticas ou pelas memórias de infância e juventude vividas naquela área (Ravagnani 2011; Silva 2012). As ruínas têm uma centralidade no cotidiano da vila, uma vez que estão localizadas em uma das bordas da praça principal, circundada pela "igreja nova", pelo salão de festas, escola, acesso à Praia do Porto, e onde são realizadas as festas religiosas e festivais de verão, entre outros eventos da comunidade.

Assim, as ruínas são referenciais importantes, marcas do tempo, paisagem da memória de muitos moradores que brincaram ao seu redor, subiram em suas paredes e ali namoraram ou passearam com a família. Como diz D. Maria, moradora do entorno da praça: "As ruínas estão ali desde que eu me entendo", numa alusão ao tempo passado e vivido junto com elas. 
As ruínas são elementos presentes nas narrativas sobre visagens: os relatos, sobretudo das crianças, falam de santas que caminham sobre sua torre, de mulas sem cabeça que correm a sua volta e indicam que há lugares que "faz muita visage" (Silveira \& Bezerra, 2012: 136; 138). Há uma mangueira "que é mal-assombrada" e que fica a poucos metros do sítio, ainda na área da praça. As crianças lidam com as visagens de forma quase lúdica, já os adultos demonstram medo $^{7}$, mas todos se relacionam de alguma forma com essa dimensão sensível da realidade.

As crianças desenham as ruínas que podem ser vistas em cartolinas utilizadas como suporte para trabalhos escolares (Figura 3). Os adultos pintam as ruínas nos muros, como se pode observar no salão de festas da igreja, localizado na praça (Figura 3). Ali as ruínas foram pintadas e emolduradas por motivos da cerâmica marajoara, constituindo o quadro que anuncia o Círio de Nossa Senhora do Rosário, que ocorre no segundo domingo de novembro.

A imagem das ruínas está presente nas placas de rua, feitas pelos próprios moradores para a sinalização ao redor da praça (Figura 3). Os desenhos da cerâmica arqueológica delimitam paisagens da vida cotidiana de Joanes e criam novas variações de formatos e cores. $\mathrm{Na}$ Pousada Ventania eles convivem entre o piso "calçadão de Copacabana" e pinturas rupestres inspiradas em grafismos disponíveis em livros (Figura 4) e que também aparecem nos muros externos da construção. Os quartos da pousada têm nomes diferentes, um deles chama-se "Pré-História". A sala da recepção reúne mapas, fotos de passeios na vila e imagens da fauna amazônica, além do souvenir, um bordado "feito pelas mulheres da vila", indicando a agregação de valor conferida pela "autenticidade" do produto.

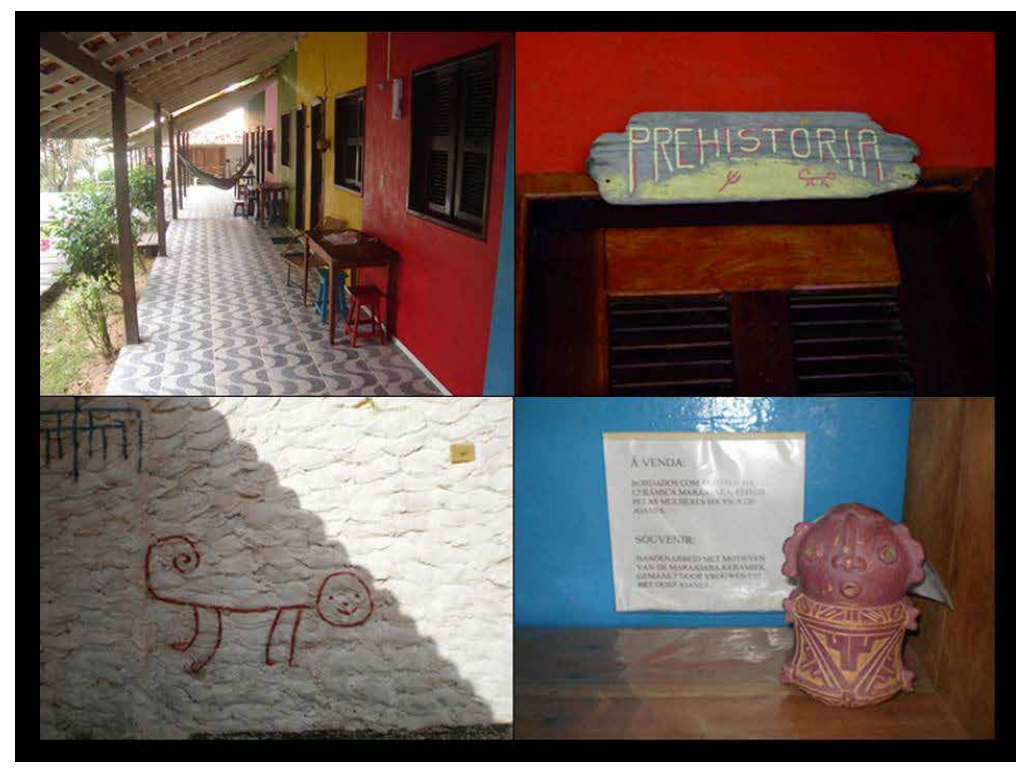

Figura 4 - Pousada Ventania. Fotos Marcia Bezerra, 2010 e 2011. 
O produto anunciado não aparece, há apenas um exemplar único de uma escultura cerâmica. O bordado "marajoara" estampa porta-copos e pares de jogo americano. Segundo algumas bordadeiras, a produção desse bordado foi estimulada por uma belga, proprietária da pousada, que passou a comprá-los para uso no café da manhã dos hóspedes e para a venda. Esse grupo de bordadeiras constitui parte do núcleo que passou a incorporar o patrimônio arqueológico no artesanato e que possibilitou a fundação da AERAJ. Cabe ressaltar que, apesar da variedade de produtos que passaram a criar e vender, os porta-copos e jogos americanos "marajoara" continuam a ser feitos, com algumas adaptações, como veremos.

A história da AERAJ começou nos anos 1990, quando o grupo de bordadeiras criou a GARAJO - Grupo de Artesãs da Vila de Joanes. O grupo ocupava uma pequena casa de pau a pique, construída em uma propriedade temporariamente cedida por um veranista estrangeiro. A precariedade das condições de trabalho, somada à dificuldade em legalizar as atividades do grupo, por pouco não resultou em sua desativação. A pequena produção era vendida para alguns estabelecimentos locais, mas a sede da GARAJO permanecia fechada por longos períodos, impedindo o reconhecimento do trabalho artesanal e o acesso dos turistas.

Em 2006, o grupo foi registrado como Associação Educativa Rural e
Artesanal da Vila de Joanes - AERAJ. A Associação não possuía local adequado para o trabalho das mulheres, resultando numa produção artesanal acanhada e de poucos benefícios financeiros. Se o artesanato já representava uma atividade de caráter secundário para as bordadeiras, a falta de perspectiva tornou-o ainda mais periférico.

Em 2010, "Leda", recém-chegada na Vila, uniu-se ao grupo de artesãs e abrigou a Associação em sua casa. $\mathrm{O}$ grupo, formado por mulheres entre 25 e 71 anos e por um jovem rapaz da comunidade, trabalhava, inicialmente, apenas na parte da manhã. Um ano depois, a AERAJ construiu uma sede própria, onde o artesanato passou a ser produzido e vendido na loja montada na parte da frente da sede. Com o aumento das vendas, outras mulheres se juntaram ao grupo, e a jornada de trabalho passou a se prolongar pelo período da tarde.

No processo de revitalização, A AERAJ - Associação Educativa Rural e Artesanal da Vila de Joanes - elegeu como sua logomarca o sítio arqueológico Joanes (PA-JO-46) (Figura 5), o que reafirma a centralidade das ruínas. Essa iniciativa mostra o surgimento de um tímido movimento de reivindicação de direitos sobre o passado - no caso sobre as ruínas -, situação que coloca os dois "grupos" da vila - "filhos de Joanes" e "forasteiros" - numa contínua disputa pelo conhecimento, domínio e gestão das ruínas. 


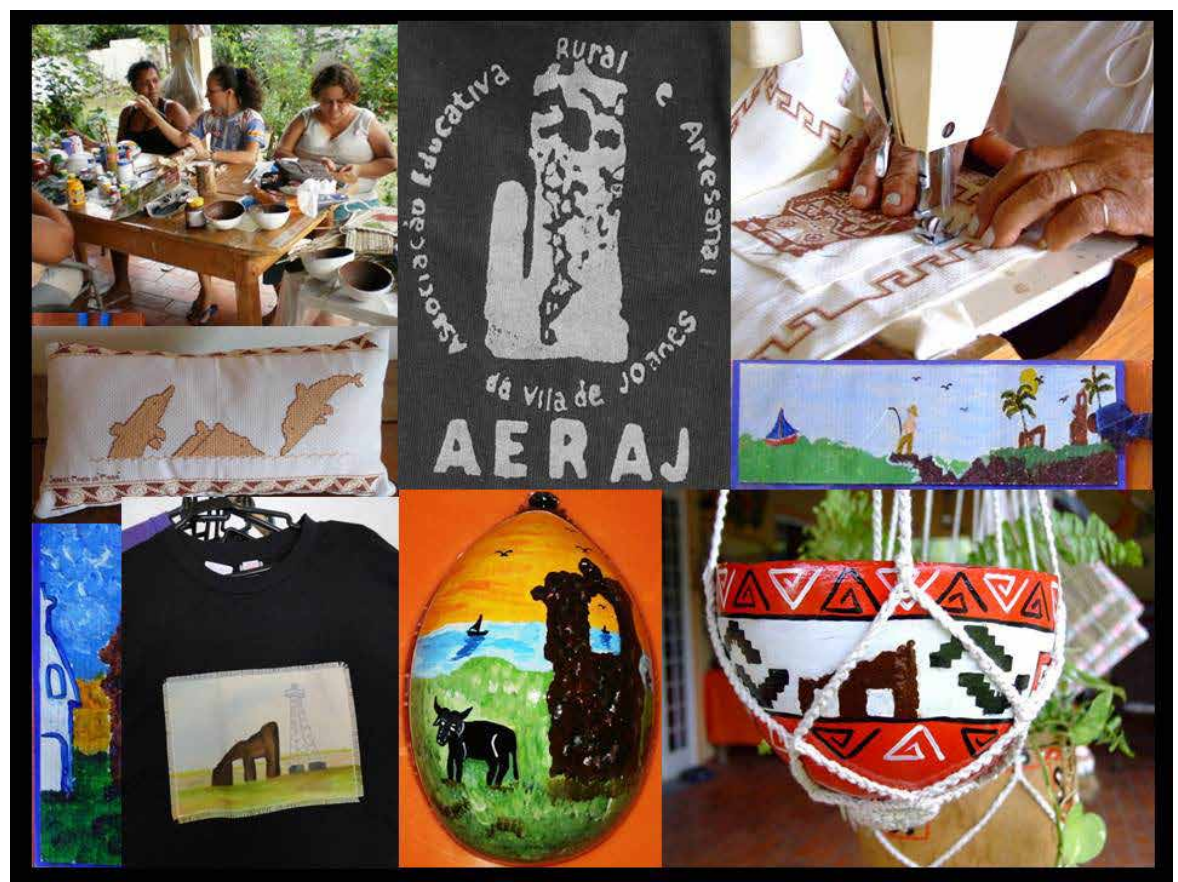

Figura 5 - AERAJ. Fotos Marcia Bezerra, 2011 e 2012

O orgulho pelo revigoramento da associação provocou mudanças sensíveis na vida das artesãs. Dalglish (2008) e Duarte (2009), ao refletirem sobre ceramistas e tecelãs do Vale do Jequitinhonha e do Triângulo Mineiro, ressaltam o papel da autoestima e do afeto nas relações estabelecidas no interior desses grupos. Dalglish (op.cit.) relata que as ceramistas deixaram de ser a "Maria do Chico", passando ele a ser o "Chico da Maria", indicando o deslocamento do papel social das mulheres que, muitas vezes, tornam-se responsáveis pela renda familiar. Lima (2012:45) afirma que os programas sociais voltados para essas comunidades de artesãos, além de promoverem a sua autoestima, geram renda e possibilidades de desenvolvimento autossustentável. Cohen, Browning e Ishino (2011: 259), ao dis- cutirem o mercado de artesanato numa comunidade em Oaxaca, México, ressaltam que "a atividade não somente deve produzir artigos valiosos, mas ela mesma deve ser valorada como uma atividade que importa ao [artesão]". O artesanato da AERAJ cumpre esse papel na vida social em Joanes.

No período de minha convivência com as artesãs observei o impacto do novo ofício não apenas no seu papel social, mas também na vaidade realçada pelo cuidado com os cortes de cabelo, unhas, roupas e maquiagem. O zelo na confecção dos produtos passou a ser espelhado no e pelo próprio corpo, que compõe, com os demais instrumentos de trabalho, um ato técnico por meio do qual se constrói o produto - a coisa - que, por sua vez, constrói a pessoa (Miller 2005). A dimensão estética do 
trabalho artesanal é impressa no próprio corpo. Gell (1998), ao discutir a relação entre arte e agência, afirma que as coisas que as pessoas criam ou usam são parte delas mesmas. $\mathrm{O}$ artesanato seria um "componente de um tipo particular de identidade social" (op.cit.: 21). Assim, criar um produto artesanal é como criar a si mesmo.

Esse processo de [auto]criação na AERAJ é coordenado por D. Leda. Um dos elementos que une as artesãs e $\mathrm{D}$. Leda é o fato de que ela, assim como a maior parte delas, não é "filha de Joanes". A distinção entre as duas categorias é dissolvida na AERAJ, especialmente quando está em jogo a disputa com a sede do município de Salvaterra, ao qual Joanes está ligada. Essa disputa vem se intensificando nos últimos anos. O turismo tem papel central nesse processo, não apenas como meio de promoção de desenvolvimento sustentável, mas, sobretudo, como sinal diacrítico da comunidade. Fortuna et al (2011: 7), ao tratar da intervenção urbana ocorrida na Praia de Iracema, em Fortaleza, argumenta que "a transformação do bairro em "mercadoria" originou outros usos por grupos distintos com "identidades partilhadas" e cujas reivindicações sobre o lugar acabaram por "recorta[r] simbolicamente esse bairro".

Na perspectiva das artesãs da AERAJ, a escolha das ruínas como símbolo da Associação é motivo de orgulho. Segundo elas, a razão para tal escolha é o anseio de que Joanes tenha sua identidade separada, distinta, "recortada" de Salvaterra, que tem como ícone o abacaxi, em razão de sua grande produção da fruta. No discurso das artesãs e de outros moradores, as ruínas são (ou têm que ser) o símbolo da vila, já que Joanes é chamada de "Vila das ruínas". Para a diretora da escola, a inclusão de sua imagem no uniforme escolar justifica-se porque: "Em Salvaterra é o abacaxi, aqui então são as ruínas!" A preocupação com a consolidação dessa denominação tem relação com o turismo, pois a referência torna o sítio conhecido, agrega valor ao lugar e promove a sua visitação.

A comodificação das paisagens de Joanes, sobretudo as ruínas do sítio de Joanes, está imbricada com a delimitação de uma fronteira identitária entre a vila de Joanes e o município de Salvaterra. A escolha das ruínas como identidade visual da AERAJ, a proposta de sua impressão no uniforme escolar e o episódio de seu cercamento pelos moradores sugerem que um "recorte simbólico" está em curso.

Apesar disso, segundo as artesãs, os moradores locais, inicialmente, não compravam o artesanato produzido por elas, apenas os turistas. Por essa razão, alguns produtos foram adequados para atender o gosto dos visitantes estrangeiros. O jogo americano bordado pela fundadora do grupo, por exemplo, e vendido em diversos pontos na vila, teve sua paleta de cores mudada da tradicional versão em vermelho, preto e branco (reprodução de urna marajoara policroma clássica), para outra em tons pastéis - do bege ao amarelo claro -, indo ao encontro da preferência dos turistas europeus que, segundo a artesã mais velha do grupo, "não gostam de cores fortes" (Figura 4). Nessa mesma 
perspectiva, a AERAJ passou a utilizar a imagem de mamíferos marinhos em seus produtos, em função do projeto de Educação Ambiental desenvolvido na vila. Em retribuição ao apoio dado pelo projeto à Associação, as artesãs passaram a se inspirar nesses exemplares da fauna local, que não faziam parte do repertório imagético original da AERAJ.

As ruínas, por sua vez, têm sido retratadas em diversos materiais produzidos pelas artesãs, seguindo um mesmo padrão de representação. Não se observam variações nem adaptações. Afinal, trata-se da identidade visual da Associação. $O$ sítio está estampado em cuias pintadas, quadros, camisetas, luminárias, colares, marcadores de livros e pequenas telas (Figura 5). Um dos principais produtos da Associação é a cuia pintada. A cuia é elemento importante no cotidiano amazônico, em razão de seus usos na alimentação (Carvalho 2007), entre outros, sendo uma antiga tradição, pelo menos desde o século XVII, na região de Santarém, no Baixo Amazonas. Lá as cuias são confeccionadas pela Associação das Artesãs Ribeirinhas de Santarém?.

Os contextos de criação das cuias das duas associações se distinguem no tempo e no espaço, mas cabe lembrar que a responsável pela revitalização da AERAJ, D. Leda, é natural de Santarém, onde sua família possuía uma loja de artesanato. No entanto, para ela, as cuias de Santarém não são tradicionais nem "antigas", pois "foi o SEBRAE que fez”. Cabral (2007), ao refletir sobre a criação e produção de objetos artesanais, destaca um ponto sensível que é a intervenção do designer na escolha de materiais, formas, cores, paisagens e cores dos produtos. No presente caso, podemos estender essa intervenção a outros atores - pesquisadores e gestores de projetos sociais, por exemplo - que impactam a produção desses objetos, chegando a modificá-los em razão de demandas distintas, como se vê na escolha de novas cores para os produtos vendidos aos turistas ou na inclusão de outros animais como elemento de troca.

A possibilidade de construir "outros mundos" com outros matizes pelo artesanato levou à mobilização de diversos elementos que compõem novos arranjos identitários, como o da "Vila das Ruínas". Assim, a invenção desses repertórios icônicos, além se referir à "invenção da tradição" (Hobsbawn \& Ranger 1984; Schaan 2006), traduz a "necessidade da invenção" (Wagner 2010: 105). Wagner (op.cit.), ao discutir sobre a relação entre a invenção e a convenção, afirma que essa necessidade se impõe, tendo em vista que ao

"'esgotarmos' nossos símbolos no
processo de usá-los, precisamos
forjar novas articulações simbólicas
se queremos reter a orientação que
possibilita o próprio significado".

Parafraseando os autores acima, a "invenção da identidade" e a "necessidade da identidade" matizam, e são matizadas, pela criatividade e eficácia empregadas no artesanato da AERAJ. Para Gell (2009: 46), a eficácia não é "consequência direta dos efeitos visuais que ela produz", mas da relação mágica que se instala entre o objeto, ele mesmo 
parte do sujeito, e o espectador, inibindo a sua razão.

Segundo o autor (2009: 222), "A fascinação está no poder do artista de fazer as coisas que produzem esses efeitos impactantes". Os efeitos não se referem apenas ao espectador, mas também ao artesão. Barreto (2008: 141), ao tratar da cerâmica arqueológica marajoara, diz que os motivos pintados na face externa dos vasilhames foram produzidos com a "clara intenção de atrair um olhar mais demorado". O repertório icônico do passado marajoara tem "eternos poderes de encantamento" (Barreto 2008: 211) exercidos sobre as artesãs que o reelaboram para manter a sua "eficácia simbólica" sobre o espectador, no presente caso, o turista.

\section{CONSIDERAÇÕES FINAIS}

Entre as narrativas da Arqueologia e as dos moradores sobre o passado de Joanes, as artesãs inventam outros discursos, nos quais as coisas que representam as relações coloniais do passado são integradas, "enganchadas" (Hodder 2012: 213), harmonizadas e, ao mesmo tempo, exorcizadas pelo pincel/ mão do artífice. As imagens reveladas pelas artesãs nos produtos da AERAJ são como narrativas visuais que compõem esse discurso poderoso, mágico, que subverte as relações do passado colonial de Joanes, mas também as do presente. Isso porque o êxito da Associação empoderou as artesãs, instaurando outros pertencimentos destacados, "recortados" (Fortuna, 2011) das demais identidades na vila.
O cercamento liderado pelas artesãs da AERAJ (Ferreira 2012) sugere a intencionalidade de "aprisionar" as ruínas do sítio arqueológico Joanes e de tomar posse, de forma simbólica, do "lugar das ruínas". Estas também são aprisionadas no artesanato, "recortando" (Fortuna et al 2011) o passado/ presente e, com isso, emaranhando as paisagens patrimoniais e as identidades.

Os múltiplos interesses das distintas comunidades de Joanes sobre o patrimônio arqueológico, além de revelarem os conflitos e as tensões ali estabelecidos, indicam que os moradores - pescadores, professores, artesãos, crianças, velhos - têm as suas próprias interpretações sobre o passado e sobre a cultura material.

As artesãs da AERAJ interpretam o passado a partir de outros arranjos. A ressonância das relações verticalizadas entre colonizadores europeus e indígenas é técnica, e simbolicamente, simetrizada nas paisagens pictóricas forjadas pelas suas mãos, como se pode ver na cuia na qual as ruínas, que representam a presença do colonizador no passado são envolvidas pelo campo em que figuram os motivos inspirados na cerâmica marajoara antiga (Figura 5).

Nesse sentido, o artesanato produzido no âmbito da AERAJ reorganiza o passado. Os novos arranjos pictóricos mesclam a iconografia pré-colonial, as ruínas históricas e as paisagens contemporâneas. Nesse processo de criação, formas, cores e imagens são deslocadas de suas dimensões espaço-temporais e reordenadas. 
A biografia das coisas durante o processo de comodificação (Appadurai 1986) se entrecruza com a biografia das artesãs durante o trabalho de reelaboração dos referenciais imagéticos do passado. O rearranjo das coisas é, ao mesmo tempo, a criação das coisas, é a criação do artífice, a criação da identidade de artífice e de outras identidades joanenses. As coisas, as artesãs e o mundo são parte da mesma coisa e estão emaranhadas de tal forma que não existem de forma independente (Hodder 2012). As coisas criadas têm agência sobre as relações entre artesãs e turistas, entre Joanes e Salvaterra, entre o passado e o presente, mostrando que o artesanato produzido pela AERAJ é uma "metáfora sólida" (Tilley, 1999) das relações entre pessoas e coisas no passado e, sobretudo, entre pessoas e coisas no presente.

\section{AGRADECIMENTOS}

Aos moradores da Vila de Joanes, especialmente o grupo de artesãs da AERAJ. À "família" da Ventania. À Funarte/Minc, que financiou parte da pesquisa de campo.

\section{NOTAS}

${ }^{1}$ http:/ / www.amam-marajo.org/

${ }^{2}$ Dados da Unidade de Saúde da Família Manoel Frazão situada na vila de Joanes.

${ }^{3}$ A esse respeito ver também Ferreira 2012; Schaan \& Marques, 2012.

${ }^{4}$ A principal pousada da vila foi construída por uma belga que não mora em Joanes. Por seu intermédio, vários de seus conter- râneos frequentam Joanes. Além dos que se hospedam na pousada, alguns têm casas na vila, enquanto outros desenvolvem ou participam de ações sociais amparados por grupos estrangeiros.

${ }^{5}$ Para uma interessante discussão sobre a lógica do consumo entre pequenas comunidades na Amazônia ver Ribeiro 2014.

${ }^{6}$ Para uma discussão sobre turismo arqueológico e sustentabilidade ver Alfonso 2012.

${ }^{7}$ Pires (2009) observou as mesmas atitudes com relação ao domínio fantástico, no seu estudo de caso sobre a categoria de "mal-assombro", entre crianças e adultos na cidade de Catingueira, na Paraíba.

${ }^{8}$ Os nomes foram trocados para preservar o anonimato dos entrevistados.

${ }^{9}$ Ver site da Associação das Artesãs Ribeirinhas de Santarém: http:/ /airacuias.wordpress.com/. Acesso em Maio de 2013.

\section{REFERÊNCIAS}

Airoza, M. \& M. Bezerra. 2011. O Lugar do Passado: A Construção da Ideia de Museu pelos Moradores da Vila de Joanes, Ilha do Marajó, Brasil. II Simpósio de Ciências Sociais - Patrimônios Culturais: Um Campo Interdisciplinar. Goiânia: Universidade Federal de Goiás.

Alfonso, L. P. 2012. Arqueologia e Turismo: sustentabilidade e inclusão social. Tese de Doutorado. Programa de Pós-Graduação em Arqueologia, Museu de Arqueologia e Etnologia, Universidade de São Paulo, São Paulo, Brasil (2v.).

Appadurai, A. (Ed.). 1986. The Social Life of Things: commodities in cultural perspective. Cambridge: Cambridge University Press.

Barreto, C. 2008. Meios Místicos de Reprodução Social: Arte e Estilo na Cerâmica Funerária da Amazônia Antiga. Programa de 
Pós-Graduação em Arqueologia: Museu de Arqueologia e Etnologia, Universidade de São Paulo, São Paulo, Brasil.

2013. Corpo, Comunicação e Conhecimento: Reflexões para a Socialização da Herança Arqueológica na Amazônia. Revista de Arqueologia 26 (1): 112-128.

Barretto, M. 2003. O imprescindível aporte das Ciências Sociais para o planejamento e a compreensão do Turismo. Horizontes $A n$ tropológicos 9 (20): 7-11.

Bezerra, M. 2011. Artesãos do Passado: um projeto de pesquisa aplicada em uma comunidade na Vila de Joanes, Ilha do Marajó, Brasil, FUNARTE/Ministério da Cultura. Relatório. Inédito.

2012a. Archaeology as allegory: the representations of archaeology in children's literature in Brazil, in From Archaeology to Archaeologies: the 'Other' Past. Editado por A. Simandiraki-Grimshaw e E. Stefanou, pp. 67-76. Oxford: BAR.

2012b. Signifying heritage in Amazon: a public archaeology project at Vila de Joanes, Marajó Island, Brazil. Chungara 44 (3): 363-373.

2012c Arqueologia, turismo e comunidades locais: reflexões de uma Turista [Arqueóloga] Aprendiz, in Turismo e Gestão do Patrimônio Arqueológico. Organizado por S.L. Figueiredo; E. Pereira e M. Bezerra, pp.149-164. Belém: Iphan.

no prelo/a. Bricolage do passado: patrimônio arqueológico, artesanato e comunidades locais na Vila de Joanes, Ilha do Marajó, Amazônia, in Multivocalidad y Activaciones Patrimoniales en Arqueología: Perspectivas desde Sudamerica. Editado por M. Rivolta, M. Montenegro, M. e L. M. Ferreira. Buenos Aires: Instituto Interdisciplinario Tilcara: Facultad de Filosofía y Letras de la Universidad de Buenos Aires.
. no prelo/b. Informação, Patrimônio e Arqueologia: reflexões a partir da Amazônia, in Informação, Patrimônio e Memória: Diálogos Interdisciplinares. Organizado por C. X. Azevedo Netto. João Pessoa: Ed. Universidade Federal de João Pessoa.

Bourdieu, P. 2002. Campo de Poder, Campo Intelectual: Itinerario de un concepto. Editorial Montressor.

Brasil. 2003. Dispõe sobre a concessão do beneficio de seguro desemprego, durante o periodo de defeso, ao pescador profissional que exerce a atividade pesqueira de forma artesanal. http://www.planalto.gov.br/ccivil_03/leis/2003/110.779. $\mathrm{htm}$. Acesso em 22/08/2013.

Cabral, F. G. S. 2007. Saberes Sobrepostos: design e artesanato na producão de objetos culturais. Dissertação de Mestrado. Pós-Graduação em Design, Pontifícia Universidade Católica do Rio de Janeiro, Rio de Janeiro, Brasil. Carvalho, L. 2007. Cuias de Santarém: tradição, mercado e mudança em comunidades artesanais da Amazônia. Textos Escolhidos de Cultura e Arte Populares 4(1): 69-78.

Cohen, E. 1984. The Sociology of Tourism: Approaches, Issues and Findings. Annual Review of Sociology 10: 373-392.

Cohen, J. H., A. Browning, e F. Al. M. Ishino. 2011. La caída de una artesanía: cestería en San Juan Guelavia, Oaxaca. Chungara 43(22): 257-266.

Crick, M. 1989. Representation of the international tourism in the social sciences: sun, sex, sights, savings, and servility. $A n$ nual Review of Anthropology 18: 307-344

Dalglish, L. 2008. Noivas da Seca: cerâmica popular do vale do Jequitinhonha. $2^{\mathrm{a}}$ ed. São Paulo: UNESP/ Imprensa Oficial do Estado de São Paulo.

Duarte, C. R. 2009. A tecelagem manual no Triângulo Mineiro: história e cultura material. Uberlândia: EDUFU. 
Elias, N. e J.L. Scotson. 2000. Os Estabelecidos e os Outsiders: sociologia das relacoões de poder a partir de uma pequena comunidade. Rio de Janeiro: Jorge Zahar.

Feldman-Bianco, B. (Org.) 2010 [1987] $A n$ tropologia das Sociedades Contemporâneas. São Paulo: Global.

Ferreira, L. G. 2012. O lugar de ver relíquias e contar história: $O$ musen presente/ausente na Vila de Joanes, Ilha do Marajó, Pará. Dissertação de Mestrado. Programa de Pós-Graduação em Antropologia, Universidade Federal do Pará, Belém, Brasil.

Ferreira. L.G. e Bezerra, M. 2012. O Lugar da Exposição: Reflexões Sobre a Gestão Comunitária do Patrimônio Arqueológico na Amazônia - Um Estudo de Caso na Vila de Joanes, Ilha do Marajó - Pará. Anais do Congresso Luso-Brasileiro de Ciências Sociais. www.conlab.ufba.br. Acesso em 17 de abril de 2012.

Ferreira, L. G. e Bezerra, M. 2013. O lugar do passado no presente: as narrativas dos Joanenses acerca de museu e patrimônio arqueológico, um estudo de caso na Ilha do Marajó, Pará, in Museologia, Patrimônio, Interculturalidade: museus inclusivos, desenvolvimento e diálogo intercultural. Organizado por M. Granato e T. Scheiner, pp. 163-178. Rio de Janeiro: Museu de Astronomia e Ciências Afins: Universidade Federal do Estado do Rio de Janeiro: Programa de Pós-Graduação em Museologia e Patrimônio.

Fortuna, C., I. Barreira, R. Bezerra e C. Gomes. 2011. Quando cidades se encontram com o "passado": revalorização patrimonialistas em Fortaleza e Coimbra. XI Congresso Luso-Brasileiro de Ciências Sociais, Salvador. www.conlab.ufba.br. Acesso em 17 de abril de 2012.

Gell, A. 1998. Art and Agency: an anthropological theory. Oxford University Press.

2009. "The Technology of Enchantment and the Enchantment of Tech- nology", in The Object Reader. Editado por F. Candlin e R. Guins, pp. 208-228. New York: Routledge.

Gmelch, G. 2003. Bebind the Smile: The working lives of Caribbean Tourism. Bloomington: Indiana University Press.

Hiller, H.L. 1976. Escapism, penetration, and response: industrial tourism in the Caribbean. Caribbean Studies 16 (2): 92-116

Hobsbawm, E. e T. Ranger (Orgs.) 1984. A invenção das tradições. Rio de Janeiro: Paz e Terra.

Hodder, I. (ed.) 2001. Archaeological Theory Today. Cambridge: Polity Press.

Hodder, I. 2012. Entangled: An Archaeology of the relationships between humans and things. Hoboken, NJ: Wiley-Blackwell.

Holtorf, C. 2006 Experience archaeology in the dream society, in Images, representations and heritage. Editado por I. Russell, pp. 161 176. New York: Springer.

. 2007a Archaeology is a Brand: the meaning of archaeology in contemporary popular culture. Walnut Creek: Left Coast Press.

2007b An archaeological fashion show: how archaeologists dress and how they are portrayed in the media, in Archaeology and the Media. Editado por T. Clarck e M. Brittain, pp. 69-88. Walnut Creek: Left Coast Press.

IBAMA. 2013. Instituto Brasileiro do Meio Ambiente e dos Recursos Naturais Renováveis. Período de Defesos no Pará. http://www.ibama.gov.br/documentos/ periodos-de-defeso-no-para. Acesso em 20/08/2013.

IBGE. 2012. Instituto Brasileiro de Geografia e Estatística. http://www.ibge.gov. br. Acesso em 05 de janeiro de 2012.

Lima, R. G. 2012. O Povo do Candeal: caminhos da louça de barro. Rio de Janeiro: Aeroplano. 
Lopes, P. R. do C. 1999. A colonização portuguesa da Ilha de Marajó: espaço e contexto arqueológico-histórico na Missão Religiosa de Joanes. Dissertação de Mestrado. Programa de Pós-Graduação em História, Pontifícia Universidade Católica do Rio Grande do Sul, Porto Alegre, Brasil.

Marques, F.L.T. e M. Bezerra. 2009. Projeto de Pesquisa Arqueológica e Educação Patrimonial na Vila de Joanes, Ilha do Marajó. Relatório. Belém. Inédito.

Miller, D. (ed.) 2005. Materiality. Durham: Duke University Press.

Molyneaux, B.L. (Ed.) 1997. Culture life of images: visual representations in Archaeology. London/ New York: Routledge.

Moser, S. 2001 Archaeological representations: the visual conventions for constructing knowledge about the past, in Archaeological Theory Today. Editado por I. Hodder, pp. 262-283. Cambridge: Polity Press.

Moser, S. e C. Gamble. 1997 Revolutionary images: the iconic vocabulary for representing human antiquity, in Culture Life of Images: visual representations in Archaeology. Editado por B.L. Molyneaux, pp. 184-212, London/New York: Routledge.

Pará. 2012. http://www.sedurb.pa.gov.br/ idh.php. Acesso em 07/01/2012.

Ravagnani, L. R. 2011. O Patrimônio Arqueológico na percep̧ão de professores e alunos da Vila de Joanes, Ilha do Marajó. Monografia/TCC. Faculdade de Ciências Sociais, Universidade Federal do Pará, Belém, Brasil.

Ribeiro, A. S. P. R. 2014. O consumo de mercadorias e suas implicações para as relações de patronagem na Comunidade Curupira (AM). Comunicação apresentada no GT 21 durante a $29^{a}$ Reunião Brasileira de Antropologia, Natal: Universidade Federal do Rio Grande do Norte.

Russell, I. (Ed.) 2006. Images, representations and heritage. New York: Springer.
Schaan, D. P. 2006. Arqueologia, público e comodificação da herança cultural: o caso da cultura Marajoara. Revista Arqueologia Pública 1: 19-30.

Schaan, D. P. 2012. Entre a tradição e a pós-modernidade: a cerâmica marajoara como símbolo da identidade 'paraense', in Diálogos antropológicos: diversidades, patrimônios, memórias. Editado por H.R. Maués e M.E. Maciel, pp. 119-150. Belém: L \& A Editora.

Schaan, D. P. e F.L.T. Marques. 2006. Preservação, conservação, pesquisa e educação patrimonial no sítio histórico de Joanes. Relatório. Iphan: Museu Paraense Emílio Goeldi.

2012. Por que não um filho de Joanes? Arqueologia e comunidades locais em Joanes, Ilha de Marajó. Revista de Arqueologia 25 (1): $106-123$.

Silva, C. A. S. 2012. O 'Coração da Camboa': Um estudo sobre as relações entre o patrimônio arqueológico e a construção do sentimento de saudade entre os (as) pescadores(as) da Vila de Joanes, Ilha do Marajó, Amazônia, Brasil. Monografia de Conclusão de Curso. Faculdade de Ciências Sociais, Universidade Federal do Pará, Belém, Brasil.

Silveira, F.L.A. da e M. Bezerra. 2012. Paisagens fantásticas na Amazônia: entre as ruínas, as coisas e as memórias na Vila de Joanes, Ilha do Marajó, in Diálogos Antropológicos: diversidades, patrimônios, memórias. Editado por H.R.Maués e M.E. Maciel, pp. 119-150. Belém: L \& A Editora.

Silverman, H. (Ed.) 2006. Archaeological Sites in Latin America. Gainsville: University Press Florida.

Tejedor, A. del C. 2009. La autenticidade en el Turismo Comunitário. Tradición, exotismo, pureza, verdade, in Cultura, comunidad y turismo: ensayos sobre el turismo comunitario em Ecuador. Coordenado por E.R. 
Ballesteros e M.A. Vintimilla, pp. 1-116. Quito: Abya-Yala.

Tilley, C. 1999. Metaphor and Material Culture. Oxford: Blackwell.

Wagner, R. 2010 [1975]. A invenção da cultura. São Paulo: Cosac Naify.

Zarankin, A., M.S. Salerno. 2010. "Sobre bonecas e carrinhos": deconstruindo as categorias "feminino" e "masculino" no passado. Dossiê Arqueologia Hoje. Cadernos de Ciências Humanas-Especiaria 11 e 12 (20 e 21): 219-240.

Recebido em 10/05/2014

Aprovado em 15/08/2014 